\title{
Obstacles and Countermeasures of Cross-strait Cooperation in Vocational Education
}

\author{
Jing SONG, Renzhong ZHOU \\ Shenzhen Polytechnic, Shenzhen, China
}

\begin{abstract}
Obstacles of cross-strait cooperation in vocational education mainly lie in negative political and policy factors, lack of long-term mechanisms concerning complementary advantages and win-win achievement, mismatching of professional certification system as well as adverse cultural and psychological factors. To realize effective cooperation and exchanges in cross-strait vocational education, it is necessary to strengthen publicity, complete laws on cooperation in running schools, achieve certificate exchanges gradually, realize system cooperation, develop university-industry cooperation, expand platforms for exchanges and cooperation and establish special expenditure guarantees so as to remove obstacles.
\end{abstract}

KEYWORD: Cross-strait vocational education, policies on vocational education, personnel training system

\section{INTRODUCTION}

After 2008, as the rebound of cross-strait policies and the fast development of vocational education in mainland China, the exchanges and cooperation in vocational education enter into a flourishing period and cross-strait vocational education exchanges and cooperation show a comforting growth momentum. Whereas, due to causes including system and psychology, there still exist many problems in the exchanges and cooperation which require profound solutions on the levels of policy and mechanism for the continuous and in-depth interaction on crossstrait vocational education. Based on theses influencing factors, analysis on the problems existing in the current exchanges and cooperation on cross-strait vocational education mainly lies in the following aspects.

\section{OBSTACLES OF PUSHING FORWARD THE EXCHANGES AND COOPERATION IN CROSS-STRAIT VOCATIONAL EDUCATION}

\subsection{Political environment and policy factors are disadvantageous to the in-depth cooperation on cross-strait vocational education.}

As to Taiwan, the principle of "Three Limitations and Six Nos" is unfavorable to the advancement of exchanges and cooperation on current cross-strait vocational education; as to the Mainland, due to the limitations caused by Regulations on ChineseForeign cooperation in running schools, it is difficult for local governments and vocational schools to push forward exchanges and cooperation on vocational education and unsuccessful cases at high rate have led to little willingness of Taiwanese running schools in the Mainland. Besides the above policy constraints, the worries of cross-strait partners on the leakage of ideology influence the advancement of cooperation as well as the assessment, supervisory and incentive mechanism of the exchanges and cooperation on cross-strait vocational education establishment.

\subsection{Lack of long-term mechanisms of complementary advantages and win-win realization}

Mutually recognized assessment and guarantee mechanisms of education quality are the foundation of complementary advantages realization concerning cross-strait vocational education, which now is the weakness of cooperation on cross-strait vocational education. In the interaction of cross-strait vocational education, expenditure guarantee, government-university-enterprise relationship and quality assessment are rarely involved. 


\subsection{Vocational certification systems are unmatched,} which has influenced the in-depth cooperation on the mutual recognition of cross-strait vocational education certificates

The "certificate system" adopted in Taiwan now is mainly based on related regulations in its Occupation Training Method, which is complete, reasonably categorized and mainly used for preferential treatments such as job opportunity and security, salary advance, promotion and employment without probation. Relatively speaking, the national vocational qualifications system adopted in the Mainland is imprecise with unsatisfying implementation effects, which are resulted from the focuses on the commonality during vocational qualification assessment and the ignorance of enterprises' practical demands. Thus, the system cannot satisfy the skilled personnel demands of enterprises' development.

\subsection{Cultural and psychological factors cause huge influences on the cooperation on cross-strait vocational education.}

Before WWII, Japan occupied Taiwan for 50 years; after 1949, the Kuomintang began to rule Taiwan and set it apart from the Mainland, which urged the formation of Taiwan's distinctive cultural traits. Influences of cultural factors are mainly on aspects including learning habits, learning adaptability, permeation of values and differences of cross-strait school running cultures. Secondly, the psychological factors of both parties concerning to cross-strait vocational education cooperation are frequently disturbed due to the few bilateral exchanges and biased factors when publicizing each other.

\section{POLICY SUGGESTIONS ON PROFOUNDLY PUSHING FORWARD THE EXCHANGES AND COOPERATION OF CROSS-STRAIT VOCATIONAL EDUCATION}

\subsection{Enhancing the publicity: The recognition of the importance of enhancing the exchanges and cooperation on cross-strait vocational education.}

Local functional government departments and local committees of Taiwan Democratic Self-Government League are required to stand in the strategic height of united front work and take the exchanges and cooperation on cross-strait vocational education as an important work of the government. During the advancement of exchanges and cooperation on cross-strait vocational education, local governments are required to overcome the fear of difficulties and positively strengthen negotiation and coordination with central ministries, Taiwan as well as sister provinces and cities. With the courage of early and pilot Implementation, local governments are asked to proactively design specific and operable policy measures as they are participants of concrete work, propagators of cross-strait friendship, students on Taiwan's advanced experience and defenders of stable development in the Mainland.

\subsection{Perfecting laws: Regulations on cooperation in running schools should be amended and perfected or cross-strait cooperation agreements should be signed for the joint advancement of long-term mechanism establishment.}

The establishment of thorough laws and long-term mechanism is considered as the foundation of deeply pushing forward the exchanges and cooperation on cross-strait vocational education. During the legislative practice of cross-strait vocational education exchanges and cooperation, the Mainland is required to positively strengthen its policy supports, complete related legal texts and procedures, and introduce legal texts or agreements to push forward the exchanges and cooperation on cross-strait vocational education. On this basis, the Mainland should enhance the negotiation with related departments in Taiwan, establish a bilateral consultation mechanism of mutual trust and mutual benefit and construct an open, competitive and mutually stimulative market and environment for cross-strait vocational education. Specific suggestions are.

\subsection{Cooperation on certificate and license:}

Mutual recognition of degrees, qualifications and skill certificates of cross-strait vocational education should be gradually realized. With the least delay, vocational education system should be perfected, certificate and license inspection and supervision system should be set up, vocational education quality should be promoted constantly and publicity should be strengthened then mutual understanding and trust between the both sides on vocational education can be advanced. Besides strict training approval and institution identification, governments are required to jointly establish skills training institutions with Taiwan, or introduce the training system and certificate identification system in Taiwan, and accept the skills certificates issued by training institutions in Taiwan. 
3.4 System cooperation: Taking the advantages of vocational education system in Taiwan, the vocational education system in the Mainland should be perfected and mutual recognition of cross-strait vocational education should be built up.

Currently, the vocational education system in Taiwan is comparatively mature; the both sides should strengthen the cooperation on vocational education system construction as Taiwan possesses education covering all levels including technical secondary schools, junior colleges, regular colleges and postgraduate schools and relatively higher level and standard in training applied talents. Before the complete establishment of modern vocational education system, local vocational colleges should be asked to take early and pilot implementations for the promotion of talent cultivation level. Thus, the exchanges and cooperation on cross-strait vocational education system can be strengthened.

\subsection{Interactive teacher resources: Channels of cross-strait teacher resources communication should vigorously developed and the advancement of teaching profession should be boosted.}

At present, the teacher resources possessing teacher certificates and vocational skill certificates (hereinafter referred to as teachers with both certificates) are relatively weak in the Mainland but relatively well-developed in vocational colleges in Taiwan. A teacher resources exchange platform for teachers on the both sides and visiting scholars should be set up to further promote the exchanges among professional teachers in cross-strait vocational colleges. On one hand, this can improve the quality of teacher with both certificates in vocational colleges in the Mainland; and on the other hand, this can help vocational colleges in Taiwan to fully release their educational resources.

\subsection{University-enterprise cooperation:}

Complementary advantages of universities and enterprises should be realized for the mutual construction of university-enterprise cooperative mechanism.

preferential policies should be introduced to constantly integrate vocational educational resources of enterprises on the both sides, advance the enthusiasm of enterprises participating in the university-enterprise cooperation, and carry out multi-level cooperation on cross-strait vocational education while taking the cross-strait universityenterprise cooperation in vocational schools as the breakthrough point. It is of great essence to reasonably release limitations, introduce fiscal and taxation preferential policies, and encourage capitals from Taiwan to join in the vocational education. For example, it is necessary to loosen requirements on application for school qualification and establishment standards, remove limitations on capitals from Taiwan used in land purchase and encourage capitals from Taiwan to run or participate in vocational education.

\subsection{Expansion of platform: Exchanges and cooperation projects should be gradually expanded, and the content and mode should be enriched.}

On the basis of current exchanges and cooperation platform on vocational education, the mode and content can be constantly enriched as the new media implementation and the new elements augmentation. Superior vocational education resources from Taiwan can be continually absorbed by the Mainland, and the cooperation can be pushed forward by new media. Exchanges and cooperation between cross-strait vocational education circles can be strengthened through the internet, such as the development of online learning materials, establishment of virtual network institutes and the supply of multiple options for learning.

\subsection{Expenditure guarantee: Special government} funding or foundation should be set up, and the expenditures required by the interaction of cross-strait vocational education can be ensured.

Different regions should analyze and appraise specifically, provide sufficient expenditure guarantee, and positively push forward the effective implementation of cross-strait vocational education exchanges and cooperative projects. Concrete suggestions are as follows:

-- As to the high costs on Mainland students living in Taiwan, local governments should establish special funds for vocational education or "crossstrait vocational education exchanges and cooperation foundation", which will allocate a certain amount of subsidies based on the project scales, increase the supports offered to key programs and eliminate the worries and concerns of Mainland students living in Taiwan.

\section{REFERENCES}

[1] Tomlinson, C. A. (2001), How to Differentiate Instruction in Mixed-ability Classrooms, 2nd ed. Alexandria, VA: ASCD. 
[2] Tomlinson, C. A., \& Strickland, C. A. (2005), Differentiation in Practice: A Resource Guide for Differentiating Curriculum. Alexandria, VA: ASCD.

[3] Wang, M. C., (1992). Adaptive Education Strategies: Building on Diversity. Baltimore: Paul H. Brookes Publishing Co.

[4] WU Qingshan. Important Subjects and Future Direction of Development of Higher Education in Taiwan. 2011 Education High-level Forum and the 24th Curriculum and Education Forum: Globalization, Educational Innovation and International Competitiveness. Taiwan: School of Education of National University of Tainan, 2011 (in Chinese)

[5] SUN Fuzhi. Strategies on Promoting Habits and Characters, Class Participation As Well As Learning Motivations and Effectiveness of Vocational College Students. Excellent Teaching, Excellent Study: Theories and Practices of University Teaching Methods, Hungkuang University. Taiwan: Honglin Press, 2009 (in Chinese) 